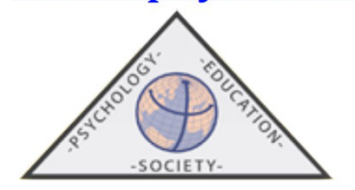

\title{
Short Forms of the Wechsler Adult Scales: a Systematic Review
}

\author{
Alba JIMÉNEZ BASCUÑ̃̂́N, Inmaculada FUENTES-DURÁ and Carmen DASÍ
}

Universitat de València

(Recibido el 8 de Octubre de 2019, Aceptado el 5 de Septiembre de 2020)

\begin{abstract}
Introduction. Since the appearance of the first WAIS scale, there has been a widespread attempt by researchers in the assessment of cognitive abilities to find short forms that facilitate the clinical practice of professionals in those situations where conditions, either because of the time available or the clinical characteristics of patients, do not require the use of an extensive tool. Objective. To carry out a systematic review of the short forms of up to four subtests extracted from the WAIS-III and WAISIV scales. Method. Conduct a search for information in the PsycINFO database and make a systematic review of the information following PRISMA guidelines. Results. Of the 47 studies found, 36 were selected for full-text revision, of which 13 were finally included in this review: 6 of the WAIS-III and 7 of the WAIS-IV. Different forms achieved good results in the quality criteria established in a variety of samples. Discussion and conclusion. There are several forms that are useful for estimating IQ, according to the samples and the quality criteria used.
\end{abstract}

Keywords: WAIS-III; WAIS-IV; IQ.

Formas breves de las escalas Wechsler para adultos: una revisión sistemática

\section{RESUMEN:}

Introducción. Desde la aparición de la primera escala WAIS, ha habido un intento generalizado por parte de investigadores/as en la evaluación de las habilidades cognitivas por encontrar formas abreviadas que faciliten la práctica clínica de los/as profesionales en aquellas situaciones en las que las condiciones, bien por el tiempo disponible o por las características clínicas de los/as pacientes, no aconsejan utilizar un instrumento extenso. Objetivo. Llevar a cabo una revisión sistemática de las formas breves de hasta cuatro subtests elaboradas a partir de las escalas WAIS-III y WAIS-IV. Metodología. Búsqueda de información en la base de datos PsycINFO y revisión sistemática de la información siguiendo el protocolo PRISMA. Resultados. De los 47 trabajos encontrados, 36 fueron seleccionados para revisar el texto completo, de los cuales 13 fueron finalmente incluidos en la revisión: 6 de la WAIS-III y 7 de la WAIS-IV. Diferentes formas obtuvieron buenos resultados en los criterios de calidad establecidos en una variedad de muestras. Discusión y conclusión. Son varias las formas breves que se muestran útiles en la estimación del CI, en función de las muestras y los criterios de calidad utilizados.

Palabras clave: WAIS-III; WAIS-IV; CI.

Correspondencia: Inmaculada Fuentes-Durá. Avenida Blasco Ibañez, 13, 46010. Valencia. E-mail: inmaculada.fuentes@uv.es 


\section{Introduction}

\section{Wechsler Scales}

Since their appearance in 1939, Wechsler scales have played a significant role in the field of cognitive skills assessment. In fact, they are one of the most widely used assessment tools by professionals in this area. This is due to the important information they offer, which has become broader and more specific through successive editions (Crawford, Allan, McGeorge, \& Kelly, 1997; Girard, Axelrod, \& Wilkins, 2010; Girard, Axelrod, Patel, \& Crawford, 2015; van Ool et al., 2018).

The first two tests, Wechsler-Bellevue Intelligence Scale and Wechsler-Bellevue Intelligence Scale II (Wechsler, 1939, 1946), provided information on intellectual functioning at performance and verbal levels and measured 7 to 69 year-olds and 10 to 79 year-olds, respectively.

The first WAIS scale (Wechsler Adult Intelligence Scale) appeared in 1955 (Wechsler, 1955). It provided three IQ scores: verbal (VIQ), performance (PIQ) and full scale (FSIQ) and consisted of the 11 subtests included in the Wechsler-Bellevue, although with some changes regarding the items and the administration and correction criteria (Wechsler, 1955): Information, Comprehension, Arithmetic, Similarities, Digit Span, Vocabulary, Digit Symbol, Picture Completion, Block Design, Picture Arrangement and Object Assembly.

In 1981 the WAIS-R was published (Wechsler, 1981). This scale maintained the same subtests and indexes, but introduced some changes in the items, administration and correction criteria and the sample was increased in the 65-69 and 70-74 year-old age groups.

The WAIS-III arrived in 1997 (Wechsler, 1997). It incorporated three new subtests (Matrix Reasoning, Letter-Number and Symbol Search) and two optional modalities of the Digit SymbolCoding subtest (Incidental Learning and Copy). The Letter-Number, Object Assembly and Symbol Search subtests were optional. Furthermore, four new scores were added referring to four cognitive factors: verbal comprehension (VC), working memory (WM), perceptual organization (PO) and processing speed (PS). VC and WM are part of VIQ and PO and PS, of PIQ. The age range in this version was from 16 to 89 years.

Finally, the WAIS-IV scale appeared in 2008 (Wechsler, 2008). This version eliminates Picture Arrangement and Object Assembly and the optional modalities from Coding, and adds three new subtests: Visual Puzzles, Figure Weights and Cancellation. The optional subtests in this version are Comprehension, Letter-Number, Picture Completion, Figure Weights and Cancellation. As for the scores, VIQ and PIQ are now called Verbal Comprehension Index (VCI) and Perceptual Reasoning Index (PRI), respectively, and together with the Working Memory Index (WMI) and the Processing Speed Index (PSI), make up the FSIQ. In addition, this version also facilitates the General Ability Index (GAI), consisting of the main subtests of VIC and PRI. The age group in this scale ranges from 16 to 89 years and 11 months of age, except for the subtests Figure Weights, Letter-Number and Cancellation, which only reach 69 years (Wechsler, 2008).

Due to their great usefulness for cognitive assessment, these scales are the instruments of preference for clinicians and researchers (Brooks \& Weaver, 2005; Sumiyoshi et al., 2016; van Duijvenbode, 
Didden, van den Hazel, \& Engels, 2016). However, the large amount of time involved in their administration may reduce their utility. According to the manuals, administration time for normal population is between 60 and 90 minutes (Wechsler 1955, 1981, 1997, 2008), while it can extend to more than 100 minutes for clinical populations (Ryan \& Rosenberg, 1984; Ryan, López, \& Werth, 1998). This is a problem in those fields characterized by the limited available time for each patient, or where patients have issues with attention, motivation, fatigue, etc. (Crawford, Allum, \& Kinion, 2008; Donell, Pliskin, Holdnack, Axelrod, \& Randolph, 2007; Kulas \& Axelrod, 2002). It is in these contexts that there is a need to develop abbreviated forms of the Wechsler scales since, as Ryan et al. (1998) point out, such short forms can reduce administration time by up to $25 \%$.

\section{Short Forms}

Brief forms have been present since the appearance of the WAIS and have accompanied the successive versions (Úbeda, Fuentes-Durá, \& Dasí, 2016). There are two methods to reduce the length of the scales: "select-item" and "select-subtest". The first consists of selecting a certain number of items from each of the subtests, keeping the scale structure intact. In the second, certain subtests are selected to be a part of the abbreviated version (without modifying the number of items).

Although both methods have obtained relatively good results, a preference for the select-subtest method is observed through literature (López, González, Vilariño, \& Linales, 2002, 2003; van Duijvenbode et al., 2016). This is because this method allows the selection of the most appropriate subtests for each occasion and patient; allows the administration of the rest of the subtests in case a more in-depth evaluation is required; and enables patients to acquire the effects of the practice and experience of dealing with progressively more difficult items. Additionally, methods of administration, correction and scoring are easier than those of the item selection (Allen et al., 1997; Mendella, McFadden, Regan, \& Medlock, 2000; Úbeda, Tomás, Dasí, Ruiz, \& Fuentes, 2017).

Three ways of estimating the full-scale IQ from the short forms are used. The first one is Tellegen \& Briggs' (1967), who suggest the Deviation Quotient (DQ), whose mean is 100 and standard deviation, 15. To calculate it, the subtests scores are converted into scaled scores according to the appropriate age group and summed to obtain the composite score, $X_{c}$. From this score, its mean $(\bar{X})$ and standard deviation $\left(S_{c}\right)$, the $\mathrm{DQ}$ is calculated with the following equation: $\mathrm{DQ}=(15 / \mathrm{Sc})(\mathrm{Xc}-\overline{\mathrm{X}})$ +100 . The second is prorating, which consists of converting the scores of the administered subtests into scaled scores, multiplying their sum by the total number of subtests, and dividing that score by the number of subtests included in the short form. The last method is regression, consisting of the elaboration of a regression equation from the sum of the scaled scores of the administered subtests classified by age. None of these approaches have established themselves as the most appropriate; all have received both positive and negative comments (Crawford et al., 2008; López et al., 2003; Ringe, Saine, Lacritz, Hynan, \& Cullum, 2002; Umfleet, Ryan, Gontkovsky, \& Morris, 2012).

On the other hand, brief forms are evaluated on the basis of quality criteria that determine their usefulness as substitutes for the Wechsler scales when estimating IQ. Some of the most widespread criteria are Resnick \& Entin's (1971), which include: a) positive and significant correlation between the short form and the full scale greater than 0.90 (Nunnally, 1978), b) non-significant 
difference between the IQ scores from the short form and the full scale, and c) high percentage of agreements in the IQ classification in categories (i.e., very superior, superior, high average, average, low average, borderline, extremely low) between the abbreviated form and the full scale. However, these are not the only criteria used to evaluate the brief forms; others can be found in literature, such as the error band, percentage of scores in the confidence interval, reliability, validity, etc. (Girard et al., 2015; Iverson, Sherman, Myers, \& Adams, 2000; Lange, Iverson, Viljoen, \& Brink, 2007; Meyers, Zellinger, Kockler, Wagner, \& Miller, 2013).

\section{Objectives of the Review}

To our knowledge, this is the first time a systematic review of the brief forms developed from the WAIS-III and WAIS-IV scales has been carried out. This review will cover the forms of up to four subtests, as those short forms with a bigger number of subtests do not save substantial time and, therefore, do not fulfill the main purpose of their design.

Our objectives are: to summarize the main short forms of WAIS-III and WAIS-IV developed of up to four subtests and establish which are the most useful in the assessment of cognitive functioning; to point out which are the most used and useful quality criteria to discriminate the best brief forms; to indicate which short forms have been the most suitable for each population type, and to determine the main limitations and delimit possible future lines of work.

\section{Method}

\section{Information Sources and Search Strategy}

This review was carried out following PRISMA guidelines (Preferred Reporting Items for Systematic reviews and Meta-Analyses) (Moher, Liberati, Tetzlaff, \& Altman, 2009).

On 21/11/2018 a search was carried out in the PsycINFO database, whose criterion was that the words "WAIS" + "short form" should appear in the title of the articles. "WAIS" + "short form" and "WAIS" + "short form" + "review" were also searched in the PubMed database. The search ran from the year 1997 to 2018, and the languages included were Spanish, English and French.

Finally, the references of the selected studies were revised and a number of publications that might be useful for this paper were selected.

\section{Inclusion Criteria and Study Selection}

A reading of the chosen works was made and those that did not develop short forms of the Wechsler III and IV scales were discarded. Thus, articles that developed or perfected equations and tables of scales, that replicated or reviewed existing short forms and that developed new forms from the WAIS and WAIS-R scales were eliminated. Additionally, the works that obtained short forms with more than four subtests from the WAIS-III and WAIS-IV were removed. 
The studies that definitely became part of this review were those that developed abbreviated forms of no more than four subtests of the WAIS-III and WAIS-IV scales, with populations of any age, clinical and non-clinical.

\section{Data Collection Process}

The data have been compiled in tables 1 and 2 (one for each Wechsler scale), which include: a) authors and year of publication, b) type of sample and number of participants, c) quality criteria, and d) summary of the main results.

A specific table was also developed for the quality criteria (table 3 ) and another one for the brief forms developed (table 4). Table 3 comprises: a) quality criteria, b) range, and c) number of articles that uses each criterion. Table 4 contains: a) version of the Wechsler scale, b) authors and year of publication, c) short form, and d) correlation between the short form and the full scale.

\section{Results}

\section{Study Selection}

A total of 47 papers were obtained from the bibliographic search, of which 36 were selected for reading. Of these, 13 met the criteria of this review and are the ones that finally formed part of the subsequent analysis. Figure 1 shows a schematic summary of the search process.

The 13 selected articles included a total of 4,722 participants (2,165 from the WAIS-III and 2,557 from the WAIS-IV). Within the WAIS-III studies, there were three studies including a control group and, in the WAIS-IV, there was one.
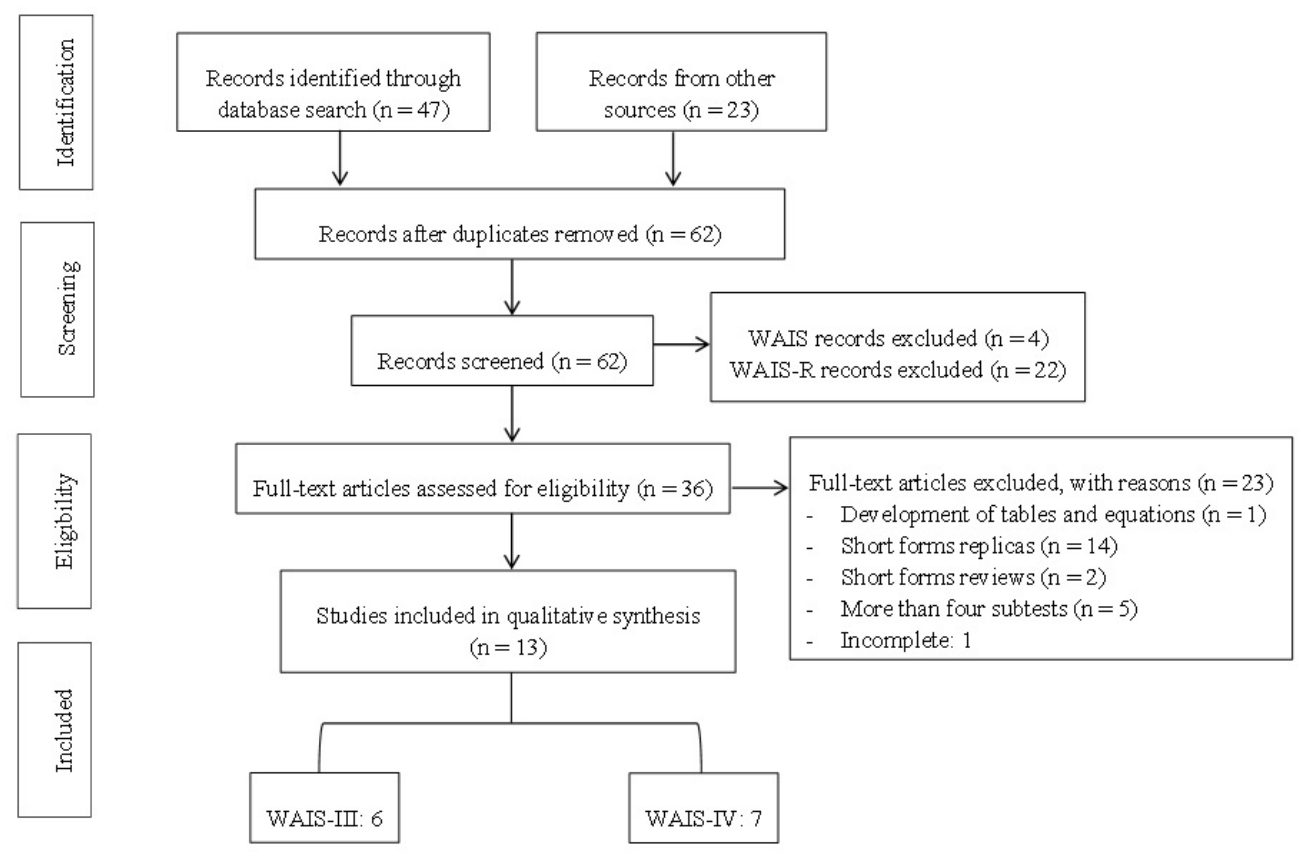

Figure 1. Schematic results of systematic study research 


\section{Short Forms of WAIS-III and WAIS-IV}

Six studies proposed two-subtest short forms as good candidates for estimating IQ (two of the WAIS-III and four of the WAIS-IV) (Denney, Ringe, \& Lacritz, 2015; Girard et al., 2015; Olivier et al., 2013; Ringe et al., 2002; Ryan, Kreiner, Gontkovsky, \& Umfleet, 2015; Sumiyoshi et al., 2016). Twelve short forms were developed in total, with four of them matching between the two scales: Vocabulary-Block Design, Information-Block Design, Vocabulary-Matrix Reasoning and Information-Matrix Reasoning (Denney et al., 2015; Ringe et al., 2002). Furthermore, two of the studies of the WAIS-IV obtained the same dyad: Similarities-Block Design (Denney et al., 2015; Ryan et al., 2015). Meanwhile, only one work from the WAIS-IV scale obtained a three-subtest short form to estimate IQ: Block Design-Similarities-Digit Span (Ryan et al., 2015). Finally, eight studies have opted for four-subtest short forms (four of the WAIS-III and four of the WAISIV) (Blyler, Gold, Iannone \& Buchanan, 2000; Fuentes, Romero, Dasí, \& Ruiz, 2010; Grégoire \& Wierzbicki, 2009; Lindau \& Najström, 2018; Ryan et al., 2015; Schrimsher, O’Bryant, O’Jile \& Sutker, 2008; Úbeda et al., 2017; van Ool et al., 2018). The eight forms obtained are different.

Table 1. Summary of the Works That Have Used the WAIS-III Scale

\begin{tabular}{|c|c|c|c|}
\hline Author & Sample & Quality criteria & Subtests of the short form \\
\hline Blyler et al. (2000) & $\begin{array}{l}\text { Sample with schizophrenia } \\
\text { and schizoaffective } \\
\text { disorder }(\mathrm{N}=41) \text { and } \\
\text { control group }(\mathrm{N}=41)\end{array}$ & $\begin{array}{l}\text { Correlation SF-FS, mean } \\
\text { difference, validity and error } \\
\text { band. }\end{array}$ & $\begin{array}{l}\text { Information, Block Design, } \\
\text { Arithmetic and Digit Symbol- } \\
\text { Coding }\end{array}$ \\
\hline Ringe et al. (2002) & $\begin{array}{l}\text { Clinical and neurological } \\
\text { sample: } \mathrm{MxD}(\mathrm{N}=253) \\
\text { (validation sample, } \mathrm{n}=57)\end{array}$ & $\begin{array}{l}\text { Correlation SF-FS, mean } \\
\text { difference, percentage } \\
\text { of agreements on the IQ } \\
\text { classification and error band. }\end{array}$ & $\begin{array}{l}\text { Vocabulary and Block Design } \\
\text { Information and Block Design } \\
\text { Vocabulary and Matrix Reasoning } \\
\text { Information and Matrix Reasoning }\end{array}$ \\
\hline $\begin{array}{l}\text { Schrimsher et al. } \\
(2008)\end{array}$ & $\begin{array}{l}\text { Neuropsychiatric sample: } \\
\text { Dem, AfD, CD, ADHD; } \\
\text { AnD, BP, SA, SZ, LD, } \\
\text { TBI, MxD (N=283) } \\
\text { (validation sample, } n=94 \text { ) }\end{array}$ & $\begin{array}{l}\text { Correlation SF-FS, error band } \\
\text { and variance prediction. }\end{array}$ & $\begin{array}{l}\text { Comprehension, Matrix } \\
\text { Reasoning, Similarities and Picture } \\
\text { Arrangement }\end{array}$ \\
\hline $\begin{array}{l}\text { Grégoire \& } \\
\text { Wierzbicki (2009) }\end{array}$ & $\begin{array}{l}\text { Standardization sample of } \\
\text { the WAIS-III }(\mathrm{N}=1104)\end{array}$ & $\begin{array}{l}\text { Correlation SF-FS, reliability } \\
\text { and VIQ-PIQ adjustment. }\end{array}$ & $\begin{array}{l}\text { Vocabulary, Similarities, Matrix } \\
\text { Reasoning and Block Design }\end{array}$ \\
\hline $\begin{array}{l}\text { Fuentes et al. } \\
\text { (2010) }\end{array}$ & $\begin{array}{l}\text { Sample with schizophrenia } \\
(\mathrm{N}=41) \text { and control group } \\
(\mathrm{N}=41)\end{array}$ & Resnick \& Entin (1971)a. & $\begin{array}{l}\text { Similarities, Picture Completion, } \\
\text { Digit Span and Digit Symbol- } \\
\text { Coding }\end{array}$ \\
\hline $\begin{array}{l}\text { Sumiyoshi et al. } \\
(2016)\end{array}$ & $\begin{array}{l}\text { Sample with schizophrenia } \\
(\mathrm{N}=150) \text { and control group } \\
(\mathrm{N}=211)\end{array}$ & $\begin{array}{l}\text { Reliability and prediction of } \\
\text { variance. }\end{array}$ & Similarities and Symbol Search \\
\hline
\end{tabular}

Note: $\mathrm{SF}=$ Short form; FS= Full scale; IQ= Intellectual quotient; VIQ= Verbal IQ; PIQ= Performance IQ; ADHD= Attentiondeficit/hyperactivity; $\mathrm{AfD}=$ Affective disorder; $\mathrm{AnD}=$ Anxiety disorder; $\mathrm{BD}=\mathrm{Bipolar}$ disorder; $\mathrm{CD}=$ Cognitive dysfunction; $\mathrm{Dem}=$ Dementia; $\mathrm{LD}=$ Learning disabilities; $\mathrm{MxD}=$ Mixed diagnoses; $\mathrm{SA}=$ Substance abuse; $\mathrm{SZ}=$ Schizophrenia; $\mathrm{TBI}=$ Traumatic brain injury.

aResnick \& Entin's (1971) criteria include: correlation SF-FS, mean difference between the IQ scores and percentage of agreements on the IQ classification. 
Table 2. Summary of the Works That Have Used the WAIS-IV Scale

\begin{tabular}{|c|c|c|c|}
\hline Author & Sample & Quality criteria & Subtests of the short form \\
\hline $\begin{array}{l}\text { Olivier et al. } \\
\text { (2013) }\end{array}$ & $\begin{array}{l}\text { Clinical sample: LD, MD, } \\
\text { CD, ADHD, AdD, SZ, SA } \\
(\mathrm{N}=149)\end{array}$ & $\begin{array}{l}\text { Correlation SF-FS, mean } \\
\text { difference and error } \\
\text { band. }\end{array}$ & $\begin{array}{l}\text { Vocabulary and Similarities } \\
\text { Similarities and Information } \\
\text { Block Design and Matrix Reasoning }\end{array}$ \\
\hline $\begin{array}{l}\text { Denney et al. } \\
\text { (2015) }\end{array}$ & $\begin{array}{l}\text { Sample with known or } \\
\text { suspected neurological } \\
\text { disorders }(\mathrm{N}=163) \\
(\text { validation sample, } \mathrm{n}=50)\end{array}$ & $\begin{array}{l}\text { Correlation SF-FS, mean } \\
\text { difference and error } \\
\text { band. }\end{array}$ & $\begin{array}{l}\text { Vocabulary and Block Design } \\
\text { Vocabulary and Matrix Reasoning } \\
\text { Vocabulary and Visual Puzzles } \\
\text { Similarities and Block Design } \\
\text { Similarities and Matrix Reasoning } \\
\text { Similarities and Visual Puzzles } \\
\text { Information and Block Design } \\
\text { Information and Matrix Reasoning } \\
\text { Information and Visual Puzzles }\end{array}$ \\
\hline $\begin{array}{l}\text { Girard et al. } \\
(2015)\end{array}$ & Clinical sample $(\mathrm{N}=482)$ & $\begin{array}{l}\text { Correlation SF-FS, mean } \\
\text { difference, error band } \\
\text { and reliability. }\end{array}$ & Digit Symbol-Coding and Information \\
\hline Ryan et al. (2015) & $\begin{array}{l}\text { Clinical sample: CVA, MS, } \\
\mathrm{AD}, \mathrm{BD}, \mathrm{DD}, \mathrm{SZ}(\mathrm{N}=122)\end{array}$ & $\begin{array}{l}\text { Percentage of } \\
\text { agreements on the IQ } \\
\text { classification }\end{array}$ & $\begin{array}{l}\text { Block Design and Similarities } \\
\text { Block Design, Similarities and Digit } \\
\text { Span } \\
\text { Block Design, Similarities, Digit Span } \\
\text { and Matrix Reasoning }\end{array}$ \\
\hline $\begin{array}{l}\text { Úbeda et al. } \\
\text { (2017) }\end{array}$ & $\begin{array}{l}\text { Sample with schizophrenia } \\
(\mathrm{N}=35) \text { and control group } \\
(\mathrm{N}=35)\end{array}$ & Resnick \& Entin (1971) & $\begin{array}{l}\text { Similarities, Visual Puzzles, Arithmetic } \\
\text { and Digit Symbol-Coding }\end{array}$ \\
\hline $\begin{array}{l}\text { Lindau \& } \\
\text { Najström (2018) }\end{array}$ & $\begin{array}{l}\text { Normal sample from } 18 \text { to } \\
74 \text { years }(\mathrm{N}=261)\end{array}$ & $\begin{array}{l}\text { Correlation SF-FS, } \\
\text { variance prediction and } \\
\text { mean difference. }\end{array}$ & $\begin{array}{l}\text { Block Design, Similarities, Arithmetic } \\
\text { and Digit Symbol-Coding }\end{array}$ \\
\hline $\begin{array}{l}\text { van Ool et al. } \\
(2018)\end{array}$ & $\begin{array}{l}\text { Sample with neurological } \\
\text { problems: EP, CND, AND } \\
\text { (WAIS-IV: N=324/ WISC- } \\
\text { III: N=986) }\end{array}$ & $\begin{array}{l}\text { Donders \& Axelrod } \\
(2002)^{b} \text { and mean } \\
\text { difference. }\end{array}$ & $\begin{array}{l}\text { Matrix Reasoning, Symbol Search, } \\
\text { Vocabulary and Arithmetic } \\
\text { Visual Puzzles, Symbol Search, } \\
\text { Vocabulary and Arithmetic }\end{array}$ \\
\hline
\end{tabular}

Note: $\mathrm{SF}=$ Short form; $\mathrm{FS}=$ Full scale; $\mathrm{IQ}=$ Intellectual quotient; $\mathrm{AD}=$ Alzheimer disease; $\mathrm{AdD}=$ Adjustment disorder; $\mathrm{ADHD}=$ Attention-deficit/hyperactivity disorder; $\mathrm{AND}=$ Acquired neurological disorder; $\mathrm{BD}=$ Bipolar disorder; $\mathrm{CD}=\mathrm{Cognitive}$ dysfunction; $\mathrm{CND}=$ Congenital neurological disorder; $\mathrm{CVA}=$ Cerebrovascular accident; $\mathrm{DD}=\mathrm{Depression}$ disorder; $\mathrm{EP}=\mathrm{Epilepsy}$; $\mathrm{LD}=$ Learning disabilities; $\mathrm{MS}=$ Multiple sclerosis; $\mathrm{MD}=$ Mood disorders; $\mathrm{SA}=$ Substance abuse; $\mathrm{SZ}=$ Schizophrenia.

aResnick \& Entin's (1971) criteria include: correlation SF-FS, mean difference between the IQ scores and percentage of agreements on the IQ classification.

'Donders \& Axelrod's (2002) criteria include: reliability, correlation SF-FS and scores in the confidence interval.

\section{Quality Criteria of the Short Forms of the WAIS-III and the WAIS-IV}

The most commonly used quality criteria on the WAIS-III and the WAIS-IV scales follow the same pattern, and have been the correlation between the short form and the full scale, the mean difference between both IQs and the error band (see table 3).

Regarding two-subtest short forms, the most used criteria have followed the previous pattern, with the correlation, the mean difference and the error band standing out. Meanwhile, the work 
that has developed a three-subtest form has only used the percentage of agreements in the IQ classification criterion. Finally, the four-subtest short forms are the most varied, using correlation, mean difference, percentage of agreements in the IQ classification, error band and reliability.

Table 3. Summary of the Quality Criteria Used in the Studies

\begin{tabular}{lcc}
\hline Criteria & Range & Number of articles \\
\hline Correlation SF-FS & $0.73-0.99$ & 11 \\
Mean difference of IQ scores & $0.07-5.66$ & 9 \\
Percentage of agreement on the IQ classification & $46 \%-95 \%$ & 4 \\
Error band & $40 \%-94 \%$ & 6 \\
Scores in the CI & $0.69-0.86$ & 1 \\
VIQ-PIQ adjustment & $96.6 \% /$ & 1 \\
Reliability & 0.05 & 4 \\
Validity & $0.92-0.95$ & 1 \\
Prediction of variance & 0.90 & 3 \\
Resnick \& Entin $(1971)^{\mathrm{a}}$ & $80 \%-94 \%$ & 2 \\
Donders \& Axelrod $(2002)^{\mathrm{b}}$ & & 1 \\
\hline
\end{tabular}

Note: $\mathrm{SF}=$ Short form; FS= Full scale; $\mathrm{IQ}=$ Intellectual quotient; $\mathrm{VIQ}=$ Verbal IQ; $\mathrm{PIQ}=$ Performance $\mathrm{IQ} ; \mathrm{CI}=$ Confidence interval.

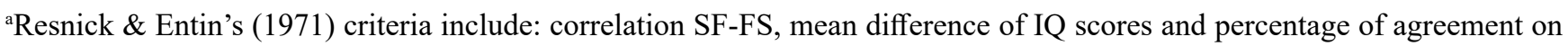
the IQ classification.

bDonders \& Axelrod's (2002) criteria include: reliability, correlation SF-FS and scores in the CI.

\section{Samples Used for Developing Short Forms in the WAIS-III and the WAIS-IV}

Both the WAIS-III and the WAIS-IV scales have a much higher number of clinical samples than normal. Furthermore, although a wide variety of diagnoses can be observed in the samples, the most prominent diagnosis is that of schizophrenia.

With respect to the studies that have obtained two-subtest short forms, all have used clinical samples with numerous different disorders, although the most repeated is schizophrenia. On the other hand, the only study that proposes a three-subtest abbreviated form uses a clinical sample that includes various disorders and diseases. As for the four-subtest short forms, the studies have used a greater proportion of clinical samples. Once again, the most frequent diagnosis has been that of schizophrenia. 
Table 4. Short Forms and Their Correlations with the Full Scale

\begin{tabular}{|c|c|c|c|}
\hline Version & Author & Brief form & Correlation \\
\hline \multirow{9}{*}{ WAIS-III } & Blyler et al. (2000) & Information, Block Design, Arithmetic and Digit Symbol-Coding & No data \\
\hline & \multirow[t]{4}{*}{ Ringe et al. (2002) } & Vocabulary and Block Design & 0.920 \\
\hline & & Information and Block Design & 0.910 \\
\hline & & Vocabulary and Matrix Reasoning & 0.900 \\
\hline & & Information and Matrix Reasoning & 0.900 \\
\hline & $\begin{array}{l}\text { Schrimsher et al. } \\
\text { (2008) }\end{array}$ & $\begin{array}{l}\text { Comprehension, Matrix Reasoning, Similarities and Picture } \\
\text { Arrangement }\end{array}$ & 0.961 \\
\hline & $\begin{array}{l}\text { Grégoire \& } \\
\text { Wierzbicki (2009) }\end{array}$ & Vocabulary, Similarities, Matrix Reasoning and Block Design & 0.950 \\
\hline & Fuentes et al. (2010) & $\begin{array}{l}\text { Similarities, Picture Completion, Digit Span and Digit Symbol- } \\
\text { Coding }\end{array}$ & $0.860-0.910^{\mathrm{a}}$ \\
\hline & $\begin{array}{l}\text { Sumiyoshi et al. } \\
(2016)\end{array}$ & \multicolumn{2}{|l|}{ Similarities and Symbol Search } \\
\hline \multirow[t]{20}{*}{ WAIS-IV } & \multirow[t]{3}{*}{ Olivier et al. (2013) } & Vocabulary and Similarities & 0.992 \\
\hline & & Similarities and Information & 0.991 \\
\hline & & Matrix Reasoning and Block Design & 0.990 \\
\hline & \multirow[t]{9}{*}{ Denney et al. (2015) } & Vocabulary and Block Design & $0.860-0.880^{\mathrm{a}}$ \\
\hline & & Vocabulary and Matrix Reasoning & $0.760-0.820$ \\
\hline & & Vocabulary and Visual Puzzles & $0.820-0.830$ \\
\hline & & Similarities and Block Design & $0.820-0.860$ \\
\hline & & Similarities and Matrix Reasoning & $0.730-0.760$ \\
\hline & & Similarities and Visual Puzzles & $0.740-0.790$ \\
\hline & & Information and Block Design & $0.840-0.860$ \\
\hline & & Information and Matrix Reasoning & 0.790 \\
\hline & & Information and Visual Puzzles & $0.770-0.800$ \\
\hline & Girard et al. (2015) & Digit Symbol-Coding and Information & 0.860 \\
\hline & \multirow[t]{3}{*}{ Ryan et al. (2015) } & Block Design and Similarities & \multirow[t]{3}{*}{ No data } \\
\hline & & Block Design, Similarities and Digit Span & \\
\hline & & Block Design, Similarities, Digit Span and Matrix Reasoning & \\
\hline & Úbeda et al. (2017) & Similarities, Visual Puzzles, Arithmetic and Digit Symbol-Coding & $0.941-0.940^{\mathrm{a}}$ \\
\hline & $\begin{array}{l}\text { Lindau \& Najström } \\
\text { (2018) }\end{array}$ & Block Design, Similarities, Arithmetic and Digit Symbol-Coding & No data \\
\hline & \multirow[t]{2}{*}{ van Ool et al. (2018) } & Matrix Reasoning, Symbol Search, Vocabulary and Arithmetic & 0.880 \\
\hline & & Visual Puzzles, Symbol Search, Vocabulary and Arithmetic & 0.880 \\
\hline
\end{tabular}

Note: $\mathrm{SF}=$ Short form; $\mathrm{FS}=$ Full scale.

anange of correlations obtained for each subsample.

\section{Discussion and Conclusion}

The Wechsler scales are enormously useful tools due to the great amount of information they provide about cognitive functioning. However, it is necessary to develop abbreviated forms which allow a rapid recognition of the state of the patient and contribute to decision-making on the direction of assessments and interventions. 
The main goal in this work has been to compile the information concerning these short forms. In order to meet this primary objective, several secondary objectives have been established. These are analyzed below:

One of the objectives has been to identify the most useful abbreviated forms to replace the full scale. In fact, several short forms have shown good performance. Taking into account the values of the correlations between the short form and the full scale, it is possible to establish some forms that are slightly superior (see table 4). Within the WAIS-III scale, Comprehension-Matrix Reasoning-Similarities-Picture Arrangement (0.961) (Schrimsher et al., 2008) and, within the WAIS-IV, Vocabulary-Similarities (0.992) (Olivier et al., 2013) stand out. However, performance in a short form does not only depend on correlation, and the results have shown the great diversity of forms that have obtained good results (see the quality criteria ranges in table 3 ) and that may be useful for estimating IQ.

With regard to quality criteria, it has been established which have been the most used and what are their values. Moreover, it has been observed that the use of these criteria remains practically stable in both scales. Thus, the criteria which seem most useful when ascertaining the value of the brief forms are: correlation between the short form and the full scale, mean difference, and error band.

In addition to these psychometric criteria, many authors also established certain conditions prior to the elaboration of the abbreviated forms. For example, some chose the subtests according to areas to be assessed or according to characteristics of the sample (Ringe et al., 2002; Ryan et al., 2015). Another precondition has been the presence in the short form of at least one subtest of each index (VCI, PRI, PSI, WMI), to obtain a global vision of the cognitive performance in each domain (Blyler et al., 2000; Lindau \& Najström, 2018).

Another objective has been to determine the most suitable short forms for each type of population. Most of the studies have opted for clinical samples, with a wide variety of disorders and medical problems. Schizophrenia is the diagnosis that stands out noticeably above others, and several short forms have proven useful in determining the IQ of people diagnosed with this condition (Fuentes et al., 2010; Schrimsher et al., 2008; Sumiyoshi et al., 2016; Úbeda et al., 2017).

Finally, this review suggests, on the one hand, that many of the subtests of the Wechsler scales and their combinations can be useful in estimating IQ and, on the other hand, it provides a listing of forms that have proven to have good results and that may be helpful for clinicians in a variety of situations and patients. Nevertheless, it should be noted that these instruments can only be recommended as screening tools that can provide an approximate vision of cognitive functioning and guide subsequent assessment or determine the patient's fit in a specific treatment group (Keefe et al., 2011; Mueller, Schmidt, \& Roder, 2015). They should not be used as tools to derive a diagnostic label that may impact the patient's future (Blyler et al., 2000; Grégoire \& Wierzbicki, 2009; Lindau \& Najström, 2018; van Ool et al., 2018).

With regard to limitations, it has been observed that there is a reduced amount of works from other fields besides the Anglo-Saxon one, with non-Caucasian patients, which makes it especially difficult to adapt and generalize the results to those patient groups that belong to other contexts and cultures. 
Another limitation is the absence of groups that are more homogeneous in terms of diagnosis. Groups with homogeneous diagnosis could help to find, if there are any, the most appropriate abbreviated forms for each type of pathology.

To conclude this review and facilitate clinicians work, several two-subtest and four-subtest short forms are recommended. The most useful short forms with two-subtests have been VocabularySimilarities and Similarities-Information (Olivier et al., 2013), both from the WAIS-IV. For the four-subtest short forms, Comprehension-Matrix Reasoning-Similarities-Picture Arrangement (Schrimsher et al., 2008) and Vocabulary-Similarities-Matrix Reasoning-Block Design (Grégoire \& Wierzbicki, 2009), both from the WAIS-III are worthy of note. If a more updated brief form is required, Similarities-Visual Puzzles-Arithmetic-Coding has obtained the best result from the WAIS-IV scale (Úbeda et al., 2017).

Furthermore, if an estimation of the two IQs (VIQ and PIQ) or the four indexes (VCI, WMI, PRI, PSI) is required, the recommended short forms are the following:

For estimating VIQ and PIQ, the most useful brief form is Vocabulary-Block Design (Denney et al., 2015; Ringe et al., 2002), from both WAIS-III and WAIS-IV scales. For estimating VCI, WMI, PRI and PSI indexes, the forms with the best results are Similarities-Picture Completion-Digit Span-Codin (Fuentes et al., 2010), from the WAIS-III, and Similarities-Visual Puzzles-ArithmeticCoding (Úbeda et al., 2017), Matrix Reasoning-Symbol Search-Vocabulary-Arithmetic and Visual Puzzles-Symbol Search-Vocabulary-Arithmetic (van Ool et al., 2018), from the WAIS-IV.

Finally, the use of prorating to estimate full scale IQ is recommended, as it is the simplest and fastest method (Bulzacka et al., 2016; Meyer et al., 2013; Olivier et al., 2013; Umfleet et al., 2012).

In view of the above, it seems appropriate to emphasize the importance of this review. Given the heterogeneity of the samples studied and the criteria evaluated, it is especially valuable to have a synthesis study such as this, so clinicians can consult the summary tables when deciding which short version to use, depending on the situation, objectives and specific sample in which the short form is going to be applied.

\section{Funding}

This work was supported by the Dirección General de Universidades, Investigación y Ciencia of the Government of the Valencian Community, Spain [grant number GV/AICO/2016/070].

\section{Conflict of Interests}

The authors declare they have no conflicts of interest.

\section{References}

Allen, D. N., Huegel, S. G., Gurklis, J. A., Jr., Kelley, M. E., Barry, E. J., \& van Kammen, D. P. (1997). Utility of WAIS-R short forms in schizophrenia. Schizophrenia Research, 26(2-3), 163-172. doi:10.1016/S0920-9964(97)00052-2 
Blyler, C. R., Gold, J. M., Iannone, V. N., \& Buchanan, R. W. (2000). Short form of the WAIS-III for use with patients with schizophrenia. Schizophrenia Research, 46(2-3), 209-215. doi:10.1016/ S0920-9964(00)00017-7

Brooks, B. L., \& Weaver, L. E. (2005). Concurrent validity of WAIS-III short forms in a geriatric sample with suspected dementia: Verbal, performance and full scale IQ scores. Archives of Clinical Neuropsychology, 20(8), 1043-1051. doi:10.1016/j.acn.2005.06.005

Bulzacka, E., Meyers, J. E., Boyer, L., Le Gloahec, T., Fond, G., Szöke, A., Leboyer, M., \& Schürhoff, F. (2016). WAIS-IV seven-subtest short form: Validity and clinical use in schizophrenia. Archives of Clinical Neuropsychology, 31(8), 915-925.

Crawford, J. R., Allan, K. M., McGeorge, P., \& Kelly, S. M. (1997). Base rate data on the abnormality of subtest scatter for WAIS-R short-forms. British Journal of Clinical Psychology, 36(3), 433444. doi:10.1111/j.2044-8260.1997.tb01250.x

Crawford, J. R., Allum, S., \& Kinion, J. E. (2008). An index-based short form of the WAIS-III with accompanying analysis of reliability and abnormality of differences. British Journal of Clinical Psychology, 47(2), 215-237. doi:10.1348/014466507X258859

Denney, D. A., Ringe, W. K., \& Lacritz, L. H. (2015). Dyadic short forms of the Wechsler adult intelligence scale-IV. Archives of Clinical Neuropsychology, 30(5), 404-412. doi:10.1093/ $\operatorname{arclin} / \operatorname{acv} 035$

Donders, J., \& Axlerod, B. N. (2002). Two-subtest estimations of WAIS-III factor index scores. Psychological assessment, 14(3), 360-364.

Donell, A., Pliskin, N., Holdnack, J., Axelrod, B., \& Randolph, C. (2007). Rapidly-administered short forms of the Wechsler Adult Intelligence Scale-3rd edition. Archives of Clinical Neuropsychology, 22(8), 917-924. doi:10.1016/j.acn.2007.06.007

Fuentes, I., Romero, M., Dasí, C., \& Ruiz, J. C. (2010). Versión abreviada del WAIS-III para su uso en la evaluación de pacientes con diagnóstico de esquizofrenia. Psicothema, 22(2), 202-207.

Girard, T. A., Axelrod, B. N., Patel, R., \& Crawford, J. R. (2015). Wechsler Adult Intelligence Scale-IV dyads for estimating global intelligence. Assessment, 22(4), 441-448. doi:10.1177/1073191114551551

Girard,T.A.,Axelrod,B.N.,\&Wilkins,L.K.(2010).ComparisonofWAIS-IIIshortformsformeasuring index and full-scale scores. Assessment, 17(3), 400-405. doi:10.1177/1073191110369763

Grégoire, J., \& Wierzbicki, C. (2009). Comparaison de quatre formes abrégées de l'échelle d'intelligence de Wechsler pour adultes-troisiéme édition (WAIS-III). European Review of Applied Psychology / Revue Européenne De Psychologie Appliquée, 59(1), 17-24. doi:10.1016/j.erap.2007.08.003

Iverson, G., Sherman, E., Myers, B., \& Adams, R. (2000). Clinical usefulness of the WAIS-R seven-subtest short form in persons with lateralized brain lesions. Journal of Cognitive Rehabilitation, 18(3), 16-20.

Keefe, R. S., Vinogradov, S., Medalia, A., Silverstein, S. M., Bell, M. D., Dickinson, D., Ventura, D., Marder, S. R. \& Stroup, T. S. (2011). Report from the working group conference on multisite trial design for cognitive remediation in schizophrenia. Schizophrenia bulletin, 37(5), 10571065 .

Kulas, J. F., \& Axelrod, B. N. (2002). Comparison of seven-subtest and Satz-Mogel short forms of the WAIS-III. Journal of Clinical Psychology, 58(7), 773-782. doi:10.1002/jclp.2009 
Lange, R. T., Iverson, G. L., Viljoen, H., \& Brink, J. (2007). Clinical validation of canadian WAISIII index short forms in inpatient neuropsychiatry and forensic psychiatry. The Clinical Neuropsychologist, 21(3), 434-441. doi:10.1080/13854040600584649

Lindau, M. \& Najström, M. (2018): Cross-cultural applicability and reduction of the American seven-subtest short form of the WAIS on a Swedish non-clinical sample. Nordic Psychology, 1-16. doi:10.1080/19012276.2018.1520643

López, M. J. L., González, J. M. R., Vilariño, C. S., \& Linales, E. T. (2003). Utilidad de las formas cortas de la escala de inteligencia de Wechsler para adultos (WAIS). Anales De Psicología, 19(1), 55-63.

López, M. J. L., González, J. M. R., Vilariño, C. S., \& Linales, E. T. (2002). Evaluación de la capacidad intelectual a través de una forma abreviada del WAIS. Revista Iberoamericana De Diagnóstico Y Evaluación Psicologica, 13(1), 147-162.

Mendella, P. D., McFadden, L., Regan, J., \& Medlock, L. (2000). Short-form prediction of WAIS-R scores in a sample of individuals diagnosed with multiple sclerosis. Applied Neuropsychology, 7(2), 102-107. doi:10.1207/S15324826AN0702_6

Meyers, J. E., Zellinger, M. M., Kockler, T., Wagner, M., \& Miller, R. M. (2013). A validated sevensubtest short form for the WAIS-IV. Applied Neuropsychology: Adult, 20(4), 249-256. doi:10 $.1080 / 09084282.2012 .710180$

Moher D, Liberati A, Tetzlaff J, Altman DG, The PRISMA Group (2009). Preferred Reporting Items for Systematic Reviews and Meta-Analyses: The PRISMA Statement. PLoS Med 6(7), e1000097. doi:10.1371/journal.pmed.1000097

Mueller, D. R., Schmidt, S. J., \& Roder, V. (2015). One-year randomized controlled trial and followup of integrated neurocognitive therapy for schizophrenia outpatients. Schizophrenia bulletin, 41(3), 604-616.

Nunnally, J. (1978). Psychometric theory (3rd ed.). New York: McGraw-Hill.

Olivier, T. W., Golden, C. J., Acevedo, A., Sterk, V. I., Espinosa, B.S., \& Spengler, K. M. (2013). WAIS-IV index and full scale intelligence quotient score differences between standard and prorated scoring methods. Archives of Assessment Psychology, 3(1), 57-77.

Resnick, R. J., \& Entin, A. D. (1971). Is an abbreviated form of the WISC valid for Afro-American children? Journal Consulting and Clinical Psychology, 36(1), 97-99.

Ringe, W. K., Saine, K. C., Lactriz, L. H., Hynan, L. S., \& Cullum, C. M. (2002). Dyadic short forms of the Wechsler Adult Intelligence Scale-III. Assessment, 9(3), 254-260.

Ryan, J. J., Kreiner, D. S., Gontkovsky, S. T., \& Umfleet, L. G. (2015). Classification accuracy of sequentially administered WAIS-IV short forms. Applied Neuropsychology: Adult, 22(6), 409-414. doi:10.1080/23279095.2014.953677

Ryan, J. J., Lopez, S. J., \& Werth, T. R. (1998). Administration time estimated for WAIS-III subtests, scales, and short forms in a clinical sample. Journal of Psychoeducational Assessment, 16(4), 315-323. doi:10.1177/073428299801600403

Ryan, J. J., \& Rosenberg, S. J. (1984). Administration time estimates for WAIS-R subtests and short forms in a clinical sample. Journal of Psychoeducational Assessment, 2(2), 125-129. doi:10.1177/073428298400200205

Schrimsher, G. W., O’Bryant, S. E., O’Jile, J. R., \& Sutker, P. B. (2008). Comparison of tetradic WAIS-III short forms in predicting full scale IQ scores in neuropsychiatric clinic settings. 
Journal of Psychopathology and Behavioral Assessment, 30(3), 235-240. doi:10.1007/ s10862-007-9066-9

Sumiyoshi, C., Fujino, H., Sumiyoshi, T., Yasuda, Y., Yamamori, H., Ohi, K., Fujimoto, M., Takeda, M., \& Hashimoto, R. (2016). Usefulness of the Wechsler Intelligence Scale short form for assessing functional outcomes in patients with schizophrenia. Psychiatry research, 245, 371378. doi:10.1016/j.psychres.2016.08.018

Tellegen, A., \& Briggs, P. F. (1967). Old wine in new skins: Grouping Wechsler subtests into new scales. Journal of consulting psychology, 31(5), 499-506.

Úbeda, R., Tomás, P., Dasí, C., Ruiz, J. C., \& Fuentes, I. (2017). Forma abreviada de la WAISIV: Estudio piloto en pacientes con esquizofrenia. International Journal of Psychology \& Psychological Therapy, 17(1), 77-86.

Umfleet, L. G., Ryan, J. J., Gontkovsky, S. T., \& Morris, J. (2012). Estimating WAIS-IV indexes: Proration versus linear scaling in a clinical sample. Journal of Clinical Psychology, 68(4), 390-396. doi:10.1002/jclp.21827

van Duijvenbode, N., Didden, R., van den Hazel, T., \& Engels, R. C. M. E. (2016). Psychometric qualities of a tetrad WAIS-III short form for use in individuals with mild to borderline intellectual disability. Developmental Neurorehabilitation, 19(1), 26-30. doi:10.3109/175184 23.2014.893265

van Ool, J. S., Hurks, P. P. M., Snoeijen-Schouwenaars, F. M., Tan, I. Y., Schelhaas, H. J., Klinkenberg, S., Aldenkamp, A.P, \& Hendriksen, J. G. M. (2018). Accuracy of WISC-III and WAIS-IV short forms in patients with neurological disorders. Developmental Neurorehabilitation, 21(2), 101-107. doi:10.1080/17518423.2016.1277799

Velthorst, E., Levine, S. Z., Henquet, C., de Haan, L., van Os, J., Myin-Germeys, I., \& Reichenberg, A. (2013). To cut a short test even shorter: Reliability and validity of a brief assessment of intellectual ability in schizophrenia-a control-case family study. Cognitive Neuropsychiatry, 18(6), 574-593. doi:10.1080/13546805.2012.731390

Wechsler, D. (1939). Wechsler-Bellevue Intelligence Scale. New York: Psychological Corporation. Wechsler, D. (1946). Wechsler-Bellevue Intelligence Scale, Form II. San Antonio, TX, US: Psychological Corporation.

Wechsler, D. (1955). Wechsler Adult Intelligence Scale. New York: Psychological Coporation.

Wechsler, D. (1981). Wechsler Adult Intelligence Scale-Revised. San Antonio, TX: Psychological Corporation.

Wechsler, D. (1997). Manual for the Wechsler Adult Intelligence Scale-III. San Antonio, TX: The Psychological Corporation.

Wechsler, D. (2008). Escala de Inteligencia de Wechsler para Adultos-Cuarta Edición: Manual técnico y de interpretación. Madrid: NCS Pearson. 